\title{
HABITUAL DISLOCATION OF PATELLA WITH QUADRICEPS CONTRACTURE- A CASE REPORT
}

\author{
P. V. Pugalenthi' ${ }^{1}$ R. Arivasan'2, T. C. Premkumar 3 , R. Karthick Raja4 , C. Rakesh ${ }^{5}$
}

1 Professor and HOD, Department of Orthopaedics, Government Rajaji Hospital, Madurai.

2 Professor, Department of Orthopaedics, Government Rajaji Hospital, Madurai.

${ }^{3}$ Assistant Professor, Department of Orthopaedics, Government Rajaji Hospital, Madurai.

${ }^{4}$ Assistant Professor, Department of Orthopaedics, Government Rajaji Hospital, Madurai.

${ }_{5}^{5}$ ostgraduate Student, Department of Orthopaedics, Government Rajaji Hospital, Madurai.

\section{ABSTRACT}

\section{BACKGROUND}

Habitual dislocation of patella is a common condition in paediatric age group where the patella dislocates whenever the knee is flexed and relocates spontaneously with extension of the knee. Proximal realignment surgery (Medial plication + lateral relea se) is a common procedure to treat this condition.

\section{CASE REPORT}

A 7-year-old female child came with chief complaints of repeated falls while walking and pain over left knee past 6 months. On clinical examination, J Sign \& apprehension test was positive. Patient was diagnosed to have habitual dislocation of left patella with quadriceps contracture for which lateral release with medial plication with V-Y plasty of quadriceps was done. RESULT: Patient was able to do full flexion of knee without lateral dislocation of patella.

\section{CONCLUSION}

In habitual dislocation of the patella with quadriceps contracture, the addition of V-Y quadricepsplasty to the proximal realignment surgery (lateral release and medial plication) will provide excellent result.

\section{KEYWORDS}

Habitual Dislocation Patella, Lateral Release, Medial Plication, V-Y Plasty of Quadriceps.

HOW TO CITE THIS ARTICLE: Pugalenthi PV, Arivasan R, Premkumar TC, et al. Habitual dislocation of patella with quadriceps contracture- A case report. J. Evolution Med. Dent. Sci. 2017;6(33):2762-2765, DOI: 10.14260/Jemds/2017/594

\section{BACKGROUND}

Habitual dislocation of patella is a common condition in paediatric age group where the patella dislocates whenever the knee is flexed and relocates spontaneously with extension of the knee. It is also known as obligatory dislocation of patella, as the patella dislocates completely with each flexion of the knee and the patient has no control over it. ${ }^{1}$ It usually presents once the child starts to walk and often it is not painful. Surgical realignment is the treatment of choice. The principle includes medialisation of patella and maintenance of proximal and distal alignment.

\section{CASE REPORT}

A 7-year-old female child came with complaints of repeated falls while walking and pain over left knee for past 6 months.

\section{On Examination}

Inspection

Left thigh muscle wasting present, patella J sign positive. (Fig No. 1)

\section{Financial or Other, Competing Interest: None}

Submission 10-03-2017, Peer Review 13-04-2017,

Acceptance 18-04-2017, Published 24-04-2017.

Corresponding Author:

Dr. C. Rakesh,

31/L5, Kasthuribhai Nagar,

Melur-625106, Madurai,

Tamilnadu.

E-mail: rock1164@gmail.com

DOI: $10.14260 /$ jemds $/ 2017 / 594$

\section{(c)}

\section{Palpation}

Patella dislocated laterally on 60-degree flexion, apprehension test positive.

Quadriceps contracture present (on keeping the patella on trochlear fossa, flexion of knee is possible only up to $60^{\circ}$ and on release, patella dislocated laterally and full flexion was achieved)

X-ray Findings (Fig No. 2): On $60^{\circ}$ flexion, patella dislocated laterally.

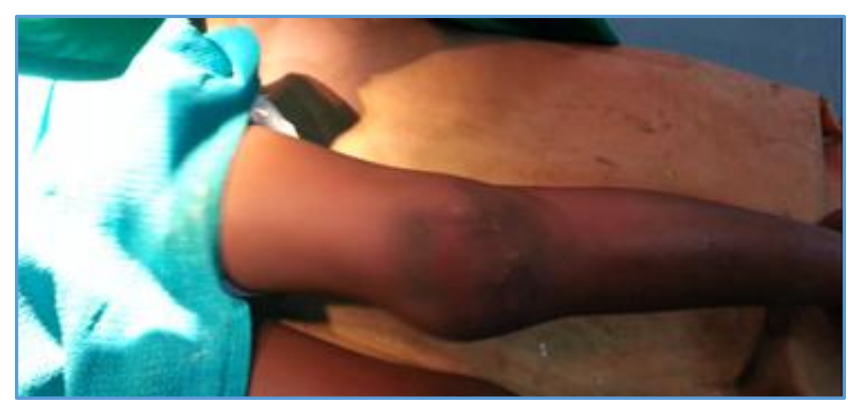

Figure 1 


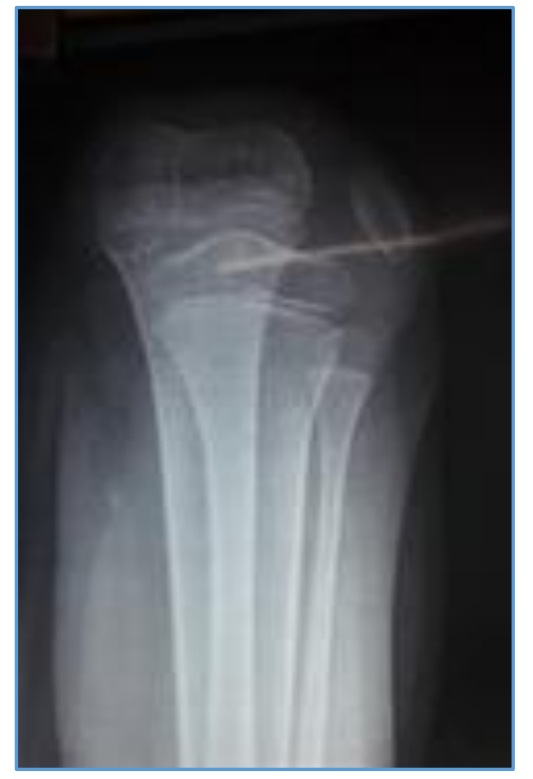

Figure 2

\section{Surgical Procedure}

Under aseptic precaution, under spinal anaesthesia and tourniquet control, left lower limb painted and draped. $15 \mathrm{~cm}$ skin incision was made on midline starting $2 \mathrm{~cm}$ distal to inferior pole of patella extending proximally (Fig. No. 3). Subcutaneous tissue incised. A cord like aberrant band which was attached to the superolateral corner of patella was divided and excised (Fig. No. 4). About $60^{\circ}$ of knee flexion was possible without patella dislocation. Beyond $60^{\circ}$, further flexion was possible only with patellar dislocation. Then V-Y quadricepsplasty was done which allowed full flexion of knee without dislocation of patella (Fig. No. 5a \& b). Then medial plication was done. Thorough wound wash given and wound closed in layers (Fig. No. 6).

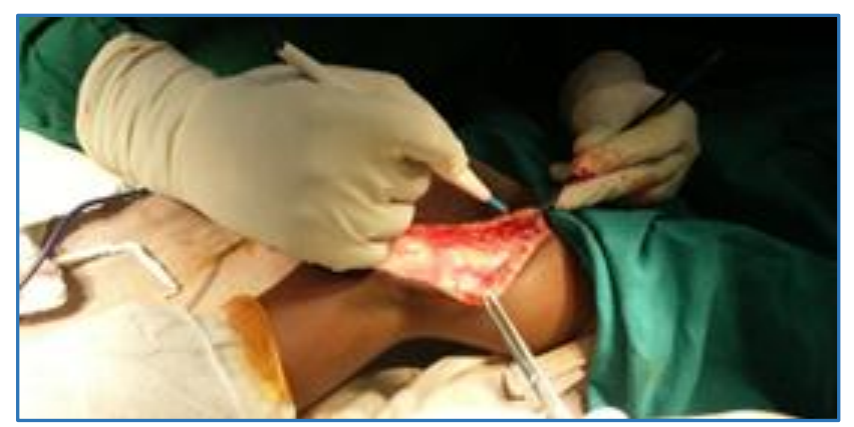

Figure 3

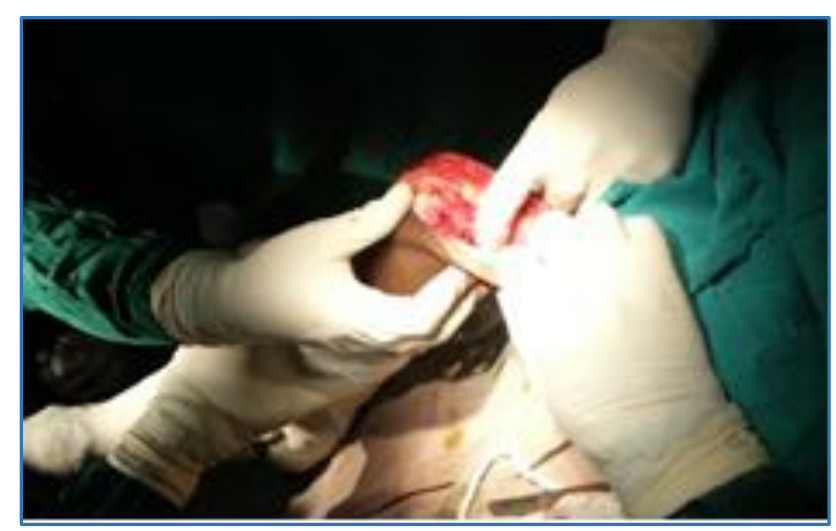

Figure 4

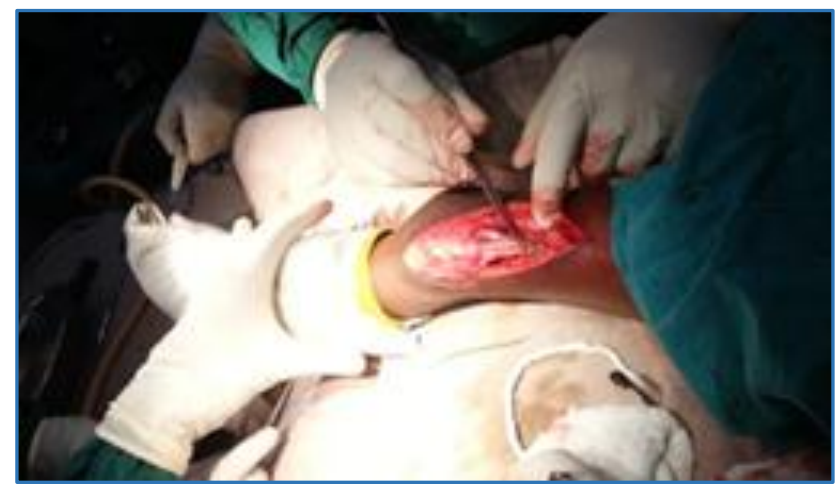

Figure $5 a$

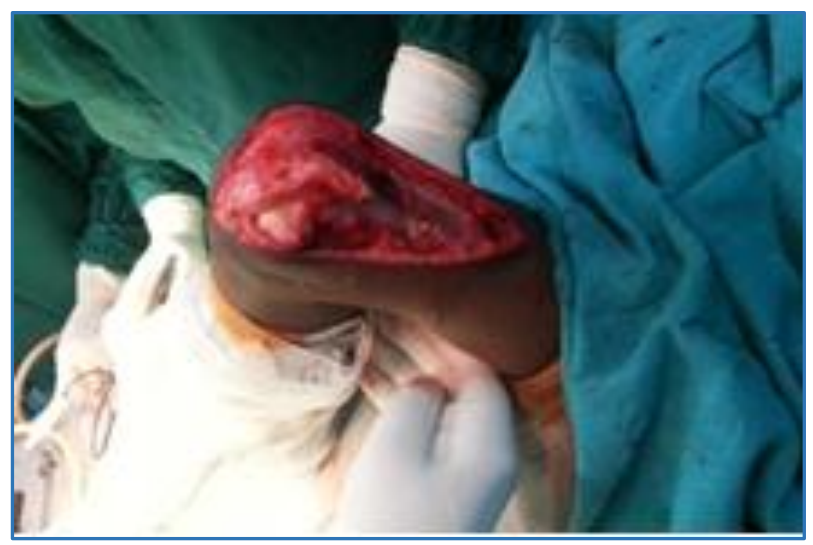

Figure $5 b$

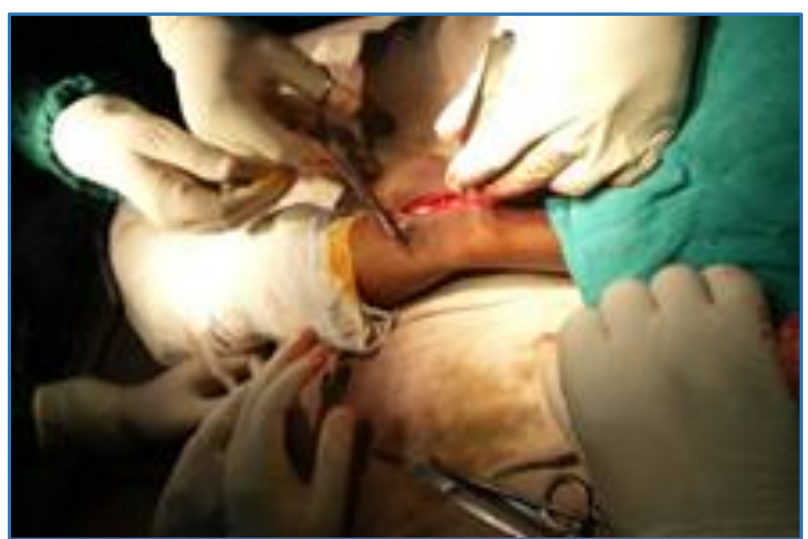

Figure 6

\section{Post-0p Protocol}

Patient was immobilised with tube slab for three weeks. Vigorous quadriceps strengthening exercise was given. Knee mobilisation was started after three weeks. After gaining $100^{\circ}$ flexion with no lag in extension, full weightbearing was started.

\section{Follow-Up Evaluation}

Patient was followed-up once a month for 7 months clinically and radiologically. Post-op x-ray (Fig no.7) confirms that patella is not dislocated laterally even in full flexion. Initially there was extensor lag which got corrected with quadriceps strengthening exercise. Finally, the range of movement was 0 to $135^{\circ}$ without patella dislocation (Fig. No. 8a \& b). Postoperatively, patient was able to do cross leg sitting and squatting without any discomfort (Fig. 9a \& b). 


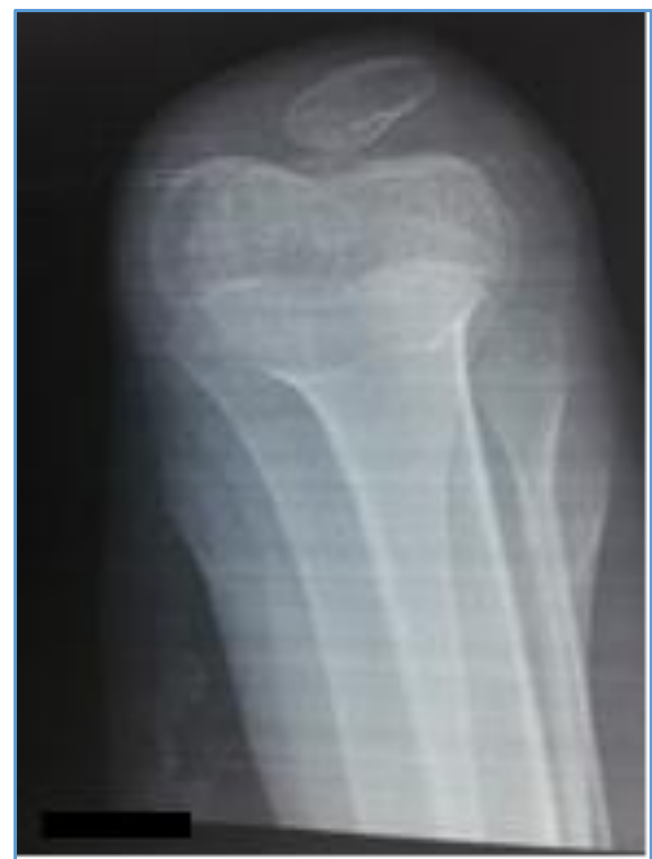

Figure 7

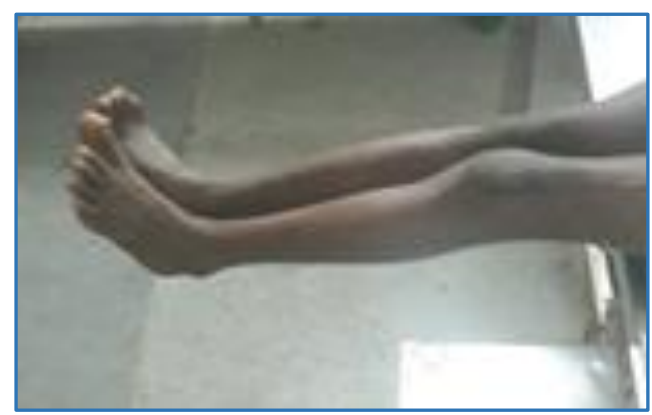

Figure 8a

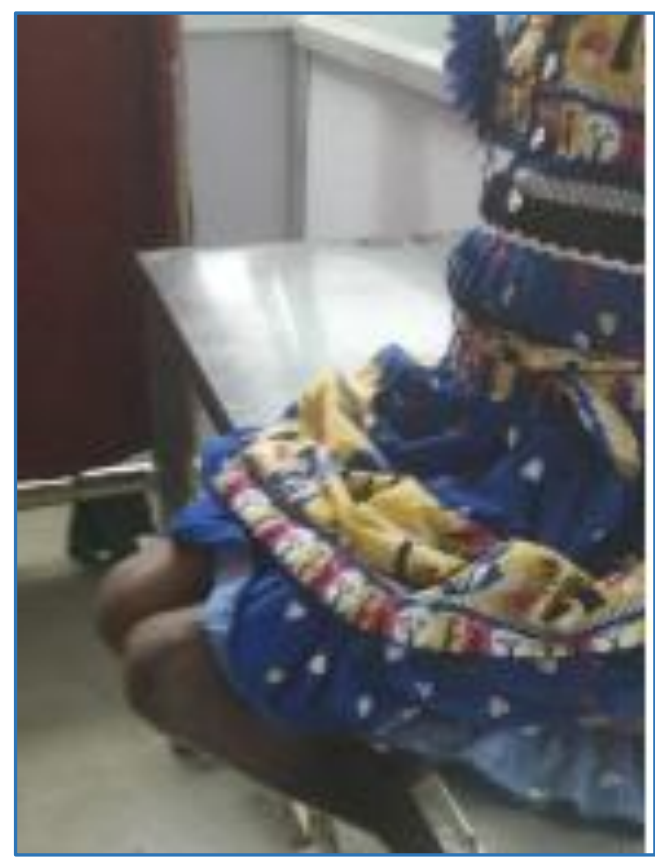

Figure $8 b$

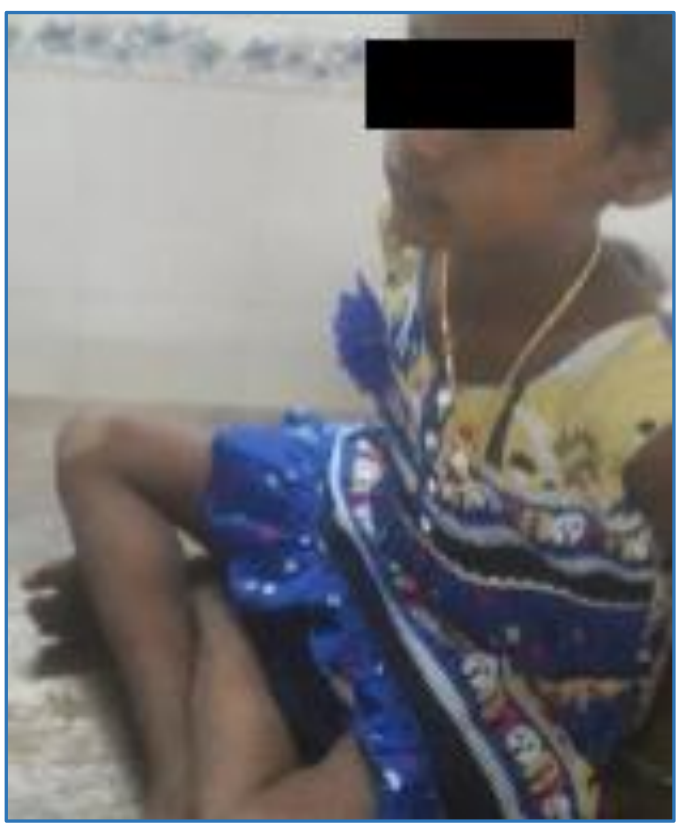

Figure $9 a$

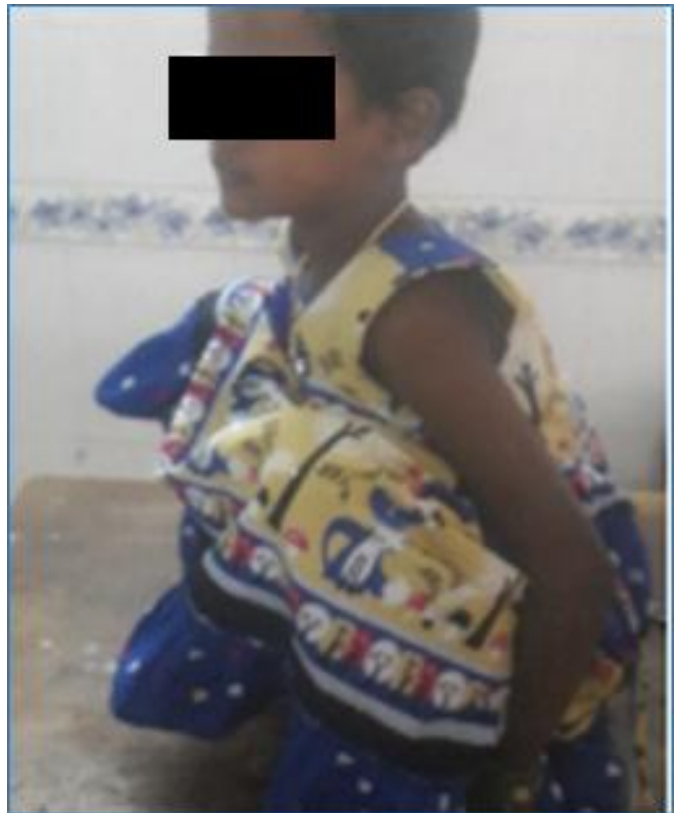

Figure 9b

\section{DISCUSSION}

Lateral dislocation of patella may present in following three forms.

- Recurrent - dislocation is episodic.

- Habitual - dislocation during flexion of knee.

- Permanent- dislocation persists in all positions.

It is never obvious in fat-covered knee. ${ }^{[2,3]}$ The cardinal sign in habitual dislocation is that if the patella is forcibly held in the midline it is not possible to flex the knee more than $30^{\circ}$ to $70^{\circ}$. It usually presents after the child starts to walk, and is often well tolerated in childhood. In children it is usually asymptomatic, but in adults it may present with features of inability to run because of the instability.[4,5]

In 1963, Jeffreys described that an abnormal attachment of the iliotibial tract to the patella will produce habitual dislocation. $^{6}$ In 1964, Gunn described that quadriceps 
contracture may lead to dislocation of the patella. ${ }^{7}$ This association of quadriceps contracture with habitual dislocation was later confirmed by Gammie (1963), LloydRoberts and Thomas (1964), Williams (1968) and Alvarez et al (1980). ${ }^{5,8-10}$ So in order to combat this, the lengthening of quadriceps tendon is an essential part of the procedure to allow the patella to remain reduced after realignment.

Surgical realignment is the treatment of choice. The principle includes medialisation of patella and maintenance of proximal and distal alignment. Surgeries performed are Insall (suprapatellar realignment) and Roux-Goldthwait operation (infrapatellar soft-tissue realignment). Proximal realignment includes release of tight lateral patellar retinaculum and vastus lateralis completely and plication of medial capsule and patellar retinaculum to strengthen the lax medial structures. Vastus medialis obliquus (VMO) was advanced \& sutured to lateral border of patella \& quadriceps, after locating patella in trochlear notch in $70^{\circ}$ flexion. Distal realignment- lateral third of patellar ligament was released from tibial tuberosity and passed underneath medial portion of patellar tendon and sutured upwards and medially to pes anserinus tendon.

In our case, we have done proximal realignment surgery which includes lateral release and medial plication and in addition to this we have done V-Y quadricepsplasty to address quadriceps contracture.

\section{CONCLUSION}

In habitual dislocation of the patella, if full flexion is not possible by keeping patella in trochlea, quadriceps contracture should be considered and in these cases, the addition of $\mathrm{V}-\mathrm{Y}$ quadricepsplasty to the proximal realignment surgery (lateral release and medial plication) will provide excellent result.

\section{REFERENCES}

[1] Eilert RE. Congenital dislocation of the patella. Clin Orthop Relat Res 2001;389:22-9.

[2] Baksi DP. Pes anserinus transposition for patellar dislocation. Long term follow up results. J Bone Joint Surg Br 1993;75(2):305-10.

[3] Joo SY, Park KB, Kim BR, et al. The 'four-in-one' procedure for habitual dislocation of the patella in children: early results in patients with severe generalised ligamentous laxity and aplasis of the trochlear groove. J Bone Joint Surg $\mathrm{Br}$ 2007;89(12):1645-9.

[4] Bergman NR, Williams PF. Habitual dislocation of the patella in flexion. J Bone Joint Surg $\mathrm{Br}$ 1988;70(3):415-9.

[5] Williams PF. Quadriceps contracture. J Bone Joint Surg Br 1968;50(2):278-84.

[6] Jeffreys TE. Recurrent dislocation of the patella due to abnormal attachment of the ilio-tibial tract. J Bone Joint Surg Br 1963;45(4):740-3.

[7] Gunn DR. Contracture of the quadriceps muscle. A discussion on the etiology and relationship to recurrent dislocation of the patella. J Bone Joint Surg Br 1964;46:492-7.

[8] Gammie WFP, Taylor JH, Urich H. Contracture of the vastus intermedius in children. A report of two cases. J Bone Joint Surg Br 1963;45:370-5.

[9] Lloyd-Roberts GC, Thomas TG. The etiology of quadriceps contracture in children. J Bone Joint Surg Br 1964;46:498-517.

[10] Alvarez EV, Munters M, Lavine LS, et al. Quadriceps myofibrosis. A complication of intramuscular injections. J Bone Joint Surg Am 1980;62(1):58-60. 